\title{
The Application of Piezoelectric Sensor as Energy Harvester from Small-scale Hydropower
}

\author{
Hidayatul Aini Zakaria ${ }^{1 *}$ and Chan Men Loon ${ }^{1}$ \\ ${ }^{1}$ School of Ocean Engineering, University of Malaysia Terengganu, 21030 Kuala, Terengganu, \\ Terengganu, Malaysia.
}

\begin{abstract}
Renewable energy technology nowadays is advancing in research and application as an alternative for non-renewable energy sources including fossil fuels and coals since it is considerably less hazardous for the environment. In recent years, many studies to harvest energy from water energy including ocean waves and hydropower has been conducted. The inherent characteristic of the piezoelectric sensor which can convert mechanical energy to electrical energy has created an alternative to generate energy from renewable sources. The main aim of this research is to harvest energy from water movements which include self-generated water waves, automated water waves, flowing water and falling water. The piezoelectric sensor used in this research is a pressurebased piezoelectric sensor which means when there is a pressure exerted on the surface, it will generate electricity. A prototype was designed and simulated by Proteus software and the prototype was fabricated for energy harvesting from water movements. In this study, four methods had been used to harvest energy from small scale hydropower where two methods are from water waves generated from a hairdryer and ultrasonic cleaner and another two methods from falling water and flowing water. The results obtained shows that harvested energy from falling water gives the best results in which it has accumulated up to $13 \mathrm{~V}$ in the same amount of time as compared to water waves and water flow.
\end{abstract}

\section{Introduction}

Malaysia mainly utilizes fossil fuels, natural gas, and coal for electricity generation. Both fossil fuel and burning coal are the main factors responsible for air pollution, polluted soil, water shortages, widespread human illness and ecosystem degradation [1] which signals the burning need for renewable energy sources. Water covers more than $70 \%$ of our planet and therefore it is such a huge reservoir for renewable energy such as ocean wave and hydropower. Ocean waves have been estimated to generate about 10000-15000 TWh of energy annually [2] and ocean water wave are principally created by wind. Ocean wave energy systems convert the kinetic and potential energy contained in the natural oscillation of the ocean wave into electricity. The wind formation begins with the wind blowing across the ocean surface, in time the top layers of wind move ahead of the lower layers. The

\footnotetext{
* Corresponding author: hidayatul@umt.edu.my
} 
friction between the layers and water surface cause the top layers to topple over to create circular eddies, forcing the water surface into wave-like the shape and passed the waveform of the water movement. The water movement causes the wave oscillates in a circular oscillation and hence the generation of ocean wave [3].

Hydropower is power derived from the energy of falling water or flowing water, swift river flow like waterfall enable the generation of electricity because the flow of water falls from the top of waterfall enable the generation of electricity [4]. The first hydro-electric power systems were developed in the 1880 's. According to the International Energy Agency (IEA), large-scale hydro-electric plants currently supply $16 \%$ of the world's electricity. However, such kind of projects requires tremendous amounts of land impoundment, dams and flood control, and often they produce environmental bearings [4] which later on will pose an economic and social impact to the community nearby the hydroelectric plants. Hydropower mostly generated from river and waterfall since the flowing water of a river produced kinetic energy and falling water also provide kinetic energy from high ground to low ground. Swift river flow likes waterfall enable the generation of electricity because the flow [5] of water falls from the top of the waterfall allows that electric generator to produce electricity [4]. The water that falls from the top of the waterfall can produce electricity by converting the mechanical energy into electrical energy. Malaysia covers a land area of 330000 sq. $\mathrm{km}$ in which $58 \%$ is low areas and $48 \%$ is highland areas. Titiwangsa, Tahan, Bintang, Kledang and Pantai Timur are highland areas in Peninsular Malaysia. Tama Abu, Iran and Kapuas Hulu Ranges are highlands in Sarawak while Crocker, Maitland, and Brassey are highlands area in Sabah. Malaysia has an average rainfall of $2540 \mathrm{~mm}$ in Peninsula and $2630 \mathrm{~mm}$ in Sabah while $3850 \mathrm{~mm}$ in Sarawak which contributes towards the abundance of streams and rivers flowing from highlands areas to lowland areas [4]. All of these geographical attributes in Malaysia may contribute towards the possibility of wave energy harvesting from hydropower.

Energy harvesting or energy scavenging is the process of extracting a small amount of energy from the ambient environment through various sources of energy [6]. Sensors nowadays are widely used due to the size and also the low power consumption of the electronic circuitry [7]. The piezoelectric material had been a good choice as a self-power source of wireless sensor network because the piezoelectric material can convert the mechanical energy to electrical energy with a very simple structure [8]. Piezoelectricity is one of the most critical approaches for vibration-based energy harvesting by incorporating a beam or a plate with piezoelectric materials [9]. The axial symmetric structure of a piezoelectric plate makes it an attractive choice for easy processing into a MEMS system [10]. A basic energy harvester will first begin with transducer since it can convert mechanical energy into useful electrical energy. The mechanical source primarily alternating source and hence it needs to convert it to direct power source and soon the energy will be used by the sensor directly or store it into an energy storage devices. In this study, the pressure-based piezoelectric plate was used to harvest energy from self-generated water wave and hydropower. Currently, many research groups had joined the bandwagon of conducting analysis on piezoelectric energy harvesting from ambient vibrations by natural energies such as solar energy, wind energy, and ocean-wave energy [11, 12, and 13]. However, investigation of assessing the piezoelectric ability to harness energy from hydropower is lacking in the literature. This study tried to fill in those research gaps and to recognize the full potential of applying the piezoelectric material in garnering energy from hydropower. 


\section{Methodology}

The circuit used in this study is shown in Figure 1 where the energy harvesting piezoelectric plate was obtained from Steiner and Martin Incorporated, the USA and other electronic components were sourced locally. The energy harvester piezoelectric plate required a properly circuit as shown in Figure 1 to increase its efficiency since the input sources are relatively low so the input has to be amplified to get a significant result. The circuit was placed in a plastic covered box to shield it from water contact and the sensor was placed outside the cover box to harvest energy from the water waves.

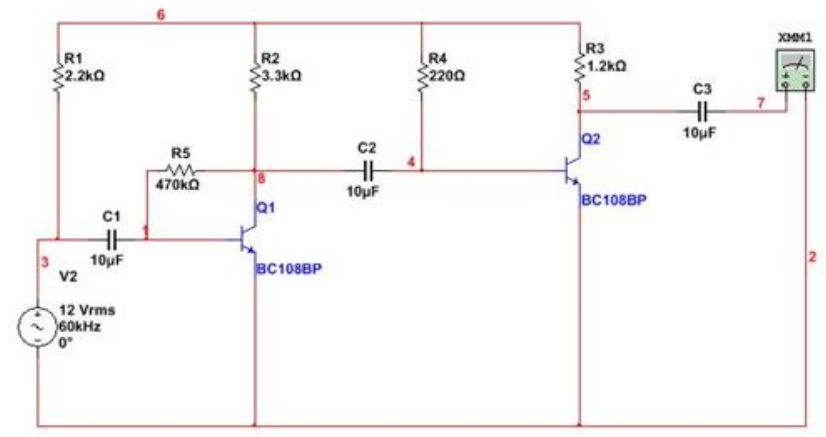

Fig. 1. Schematic drawing of the circuit used in this study

In this study, four methods had been used to harvest energy from small scale hydropower where two methods are from water waves generated from a hairdryer and ultrasonic cleaner and another two methods from flowing water and falling water at a designated distance.

\section{Results and discussion}

In this section, the robustness and efficiency of the piezoelectric energy harvester were analyzed by examining the generated power. This method utilizes hair dryer as the driving force that generates small ripples of water in a basin where the piezoelectric plate had been fully shielded with two plastic bags and the sensor was appended to the side of the water basin using black tapes. Two different types of waves were generated using the hair dryer, which generated weak and aggressive wind waves respectively. Table 1 shows the voltage accumulated from the self-generated water wave. Voltage accumulated from weak gusty wind only shows $2.204 \mathrm{~V}$ and strong gusty wind can accumulate up to $4.512 \mathrm{~V}$. Table 1 has shown that strong gusty wind will cause the piezoelectric energy harvester to garner more voltages as opposed to the weak gusty wind. The water wave generated by strong gusty wind will make more ripples on the surface of the water and the fetch will be larger, the ripples that created will be more than weak gust and the ripples won't disappear once the winds stop. The ripples created then will hit the surface of the piezoelectric sensor. When pressure is exerted on the surface, the sensor will generate electricity. Thus, weak gusty wind creates weak ripples and it affects the voltage accumulated while strong gusty wind will accumulate more energy than weak gusty winds. 
Table 1. The voltage accumulated in 30 minutes using a hair dryer as a wind source

\begin{tabular}{|l|l|l|}
\hline \multicolumn{1}{|c|}{$\begin{array}{c}\text { Type } \\
\text { of wave } \\
\text { Time }\end{array}$} & $\begin{array}{l}\text { Weak } \\
\text { Gusty } \\
\text { Wind }\end{array}$ & $\begin{array}{l}\text { Strong } \\
\text { Gusty } \\
\text { Wind }\end{array}$ \\
\hline 5 mins & $0.39 \mathrm{v}$ & $0.524 \mathrm{v}$ \\
\hline $10 \mathrm{mins}$ & $0.741 \mathrm{v}$ & $1.288 \mathrm{v}$ \\
\hline $15 \mathrm{mins}$ & $1.109 \mathrm{v}$ & $1.534 \mathrm{v}$ \\
\hline 20 mins & $1.498 \mathrm{v}$ & $2.578 \mathrm{v}$ \\
\hline 25 mins & $1.943 \mathrm{v}$ & $3.562 \mathrm{v}$ \\
\hline 30 mins & $2.204 \mathrm{v}$ & $4.512 \mathrm{v}$ \\
\hline
\end{tabular}

For flowing water experiment, the water flowed into the self-designed tunnel to harvest energy. When the water flowed inside the tube, the water will exert pressure on the piezoelectric sensor and hence generate electricity. The piezoelectric sensor was placed vertically at a different distance to study the effect of distances on generated voltage. Table 2 shows the voltage accumulated from flowing water, the highest voltage accumulated is $1.59 \mathrm{~V}$ and the lowest is $0.59 \mathrm{~V}$. When the distance between the water flow increases, the voltage that accumulated is decreasing with distance which correlates that less impact on the sensor will induce lower voltage generation.

Table 2. The voltage accumulated from water flow

\begin{tabular}{|l|l|l|l|l|}
\hline \multicolumn{1}{|r|}{ Distance $(\mathrm{cm})$} & 4.5 & 11.8 & 19.1 & 26.4 \\
$\begin{array}{l}\text { Readings } \\
\text { (Voltage) }\end{array}$ & & & & \\
\hline 1 & $0.36 \mathrm{v}$ & $0.21 \mathrm{v}$ & $0.19 \mathrm{v}$ & $0.15 \mathrm{v}$ \\
\hline 2 & $0.22 \mathrm{v}$ & $0.31 \mathrm{v}$ & $0.16 \mathrm{v}$ & $0.12 \mathrm{v}$ \\
\hline 3 & $0.36 \mathrm{v}$ & $0.20 \mathrm{v}$ & $0.19 \mathrm{v}$ & $0.11 \mathrm{v}$ \\
\hline 4 & $0.33 \mathrm{v}$ & $0.21 \mathrm{v}$ & $0.26 \mathrm{v}$ & $0.10 \mathrm{v}$ \\
\hline 5 & $0.32 \mathrm{v}$ & $0.22 \mathrm{v}$ & $0.24 \mathrm{v}$ & $0.11 \mathrm{v}$ \\
\hline $\begin{array}{l}\text { Voltage } \\
\text { accumulated }\end{array}$ & $1.59 \mathrm{v}$ & $1.15 \mathrm{v}$ & $1.04 \mathrm{v}$ & $0.59 \mathrm{v}$ \\
\hline
\end{tabular}

Figure 2 shows how pressure changes across the tube which follows the Bernoulli's equation as stated in Equation 1 below (Miller, Vandome, \& McBrewster, 2010):

$$
P+\frac{1}{2} \rho V^{2}+\rho g h=\text { constant }
$$

where $\mathrm{P}=$ pressure,

$\mathrm{h}=$ height

$\rho=$ density of fluid

$\mathrm{V}=$ velocity

$\mathrm{g}=$ gravitational force 


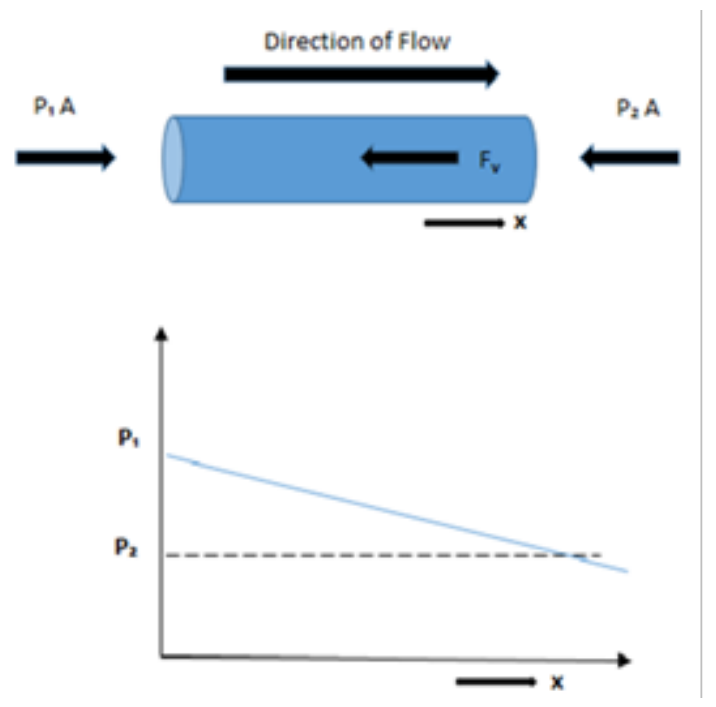

Fig. 2. Rate of pressure changes across a tube

The Bernoulli's Principle which was discovered in 1783 by a Swiss physicist and mathematician, David Bernoulli, had shown the relationships between the pressure, density, and velocity at every point in a fluid [14]. Initially in this part of this study, when the water flows from the starting point and to some distances, the pressure will begin to decrease. The same phenomenon occurred in this water flow energy harvesting experiment when the distance from the sensor and the water source is $4.5 \mathrm{~cm}$, it generated large voltage up to $1.59 \mathrm{~V}$ because the pressure drop was still not obvious until $26.4 \mathrm{~cm}$ where the accumulated voltage is only $0.59 \mathrm{~V}$. Optimum water flow rate should be used since pressure increased when the water flow rate is increased [15], so the efficiency can be increased and improved.

A small scale hydro-power station was developed as shown in Figure 3 where the piezoelectric energy harvester was strategically positioned to harvest energy from the movement of water falling from tap at various heights. Table 3 shows the voltage accumulated by harvesting of energy from falling water. The height in this experiment is referred to the height of the chair, 5 chairs were used to determine the difference between the voltage accumulated. The thickness of 1 chair is $4.5 \mathrm{~cm}$ and the gap between the chairs is approximately $2.8 \mathrm{~cm}$. When there are 5 chairs, the height is about $30.9 \mathrm{~cm}$ which mean the distance between the sensor and the water source is near. This process shares the same concept with waterfall. The voltage accumulated from falling water was rather higher than the others. 


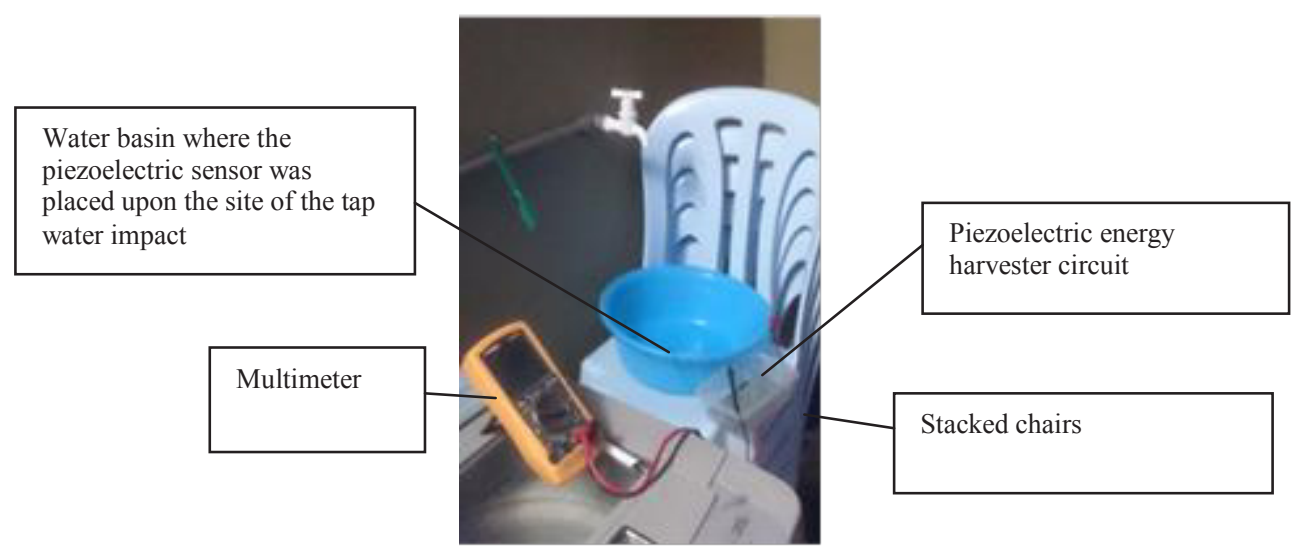

Fig. 3. Energy harvesting from falling water

Table 3. The voltage accumulated from falling water

\begin{tabular}{|l|l|l|l|l|l|}
\hline Height(cm) & & & & & \\
$\begin{array}{l}\text { Readings } \\
\text { (Voltage) }\end{array}$ & 4.5 & 11.8 & 19.1 & 26.4 & 30.9 \\
\hline 1 & $1.56 \mathrm{v}$ & $3.09 \mathrm{v}$ & $2.86 \mathrm{v}$ & $2.12 \mathrm{v}$ & $1.56 \mathrm{v}$ \\
\hline 2 & $1.69 \mathrm{v}$ & $2.63 \mathrm{v}$ & $2.91 \mathrm{v}$ & $2.45 \mathrm{v}$ & $1.69 \mathrm{v}$ \\
\hline 3 & $2.22 \mathrm{v}$ & $2.58 \mathrm{v}$ & $2.70 \mathrm{v}$ & $2.63 \mathrm{v}$ & $2.22 \mathrm{v}$ \\
\hline 4 & $2.26 \mathrm{v}$ & $2.85 \mathrm{v}$ & $2.42 \mathrm{v}$ & $3.76 \mathrm{v}$ & $2.26 \mathrm{v}$ \\
\hline 5 & $1.46 \mathrm{v}$ & $2.73 \mathrm{v}$ & $2.72 \mathrm{v}$ & $1.82 \mathrm{v}$ & $1.45 \mathrm{v}$ \\
\hline $\begin{array}{l}\text { Voltage } \\
\text { accumulated }\end{array}$ & $8.24 \mathrm{v}$ & $13.88 \mathrm{v}$ & $13.65 \mathrm{v}$ & $12.78 \mathrm{v}$ & $9.18 \mathrm{v}$ \\
\hline
\end{tabular}

The higher the pressure, the electricity that generated by the sensor is higher. This can be explained by the theory of hydrostatics, given the equation is:

$$
P=h \rho g
$$

where: $\mathrm{P}=$ pressure,

$\mathrm{h}=$ height

$\rho=$ density of fluid

$\mathrm{g}=$ gravitational force.

The density of water and the gravitational force is fixed, the falling water pulls the falling water to the surface of the piezoelectric sensor. The deflection of the sensor will increase due to the higher pressure and thus generate more electricity. But there is slightly low voltage accumulated at $4.5 \mathrm{~cm}$, the result is affected by the characteristic of the piezoelectric sensor. When only one chair is used, the distance from the water source and the sensor supposed to be high, thus when the water hit the sensor it will generate more 
electricity due to the large pressure. The performance of the piezoelectric sensor will be affected once the sensor had direct contact with water, and this shows why the voltage accumulated is rather low. When 1 chair is used to determine the height between the water source and the sensor, the pressure should be higher according to the theory but it seems that the sensor only able to harvest $8.24 \mathrm{~V}$ only. This result was influenced by the characteristic of the sensor. Most of the power generation from the waterfall, they harvest energy from the sound vibration of the turbine and didn't harvest energy straight using the piezoelectric sensor. In this research, it can be seen using piezoelectric sensor harvest energy direct from falling water pressure can be a potential for future but still, it needs a proper design and also the consideration of the type of piezoelectric sensor used in the experiment.

\section{Conclusion}

In conclusion, the piezoelectric energy harvesting from water waves and hydropower was conducted. The highest voltage accumulated from water wave was $4.512 \mathrm{~V}$ because the strong gusty wind will create more ripples and the frequency of the ripples that will hit the surface of the sensor will be more often, hence generating more energy. Results from experiments involving flowing water and falling water have shown that $1.59 \mathrm{~V}$ was accumulated during energy harvesting from water flow. The nearer between the sensor and the water source, the lower the pressure drop. Falling water shows the best result because it accumulated the highest energy that was $13.88 \mathrm{~V}$ because it obeys the Bernoulli's equation. From this study, it can be concluded that energy harvesting from falling water in particular waterfalls is an attractive alternative for energy source considering the geographical attributes of Malaysia which have an abundance of waterfalls in every state. However, the type of piezoelectric sensor, as well as the circuits, should be properly designed to ensure the durability of the piezoelectric energy harvester.

The type of piezoelectric sensor was very crucial when comes to energy harvesting. From the previous researches, many of the researches harvest energy from ocean wave or water wave using vibration but in this research pressure based sensor is used. In future, the piezoelectric sensor that used in the research must be chosen wisely to obtain the best results. Although the circuit used in this research can amplify the input sources, still sometimes it is not stable and may obtain some negative value. To overcome this problem, the recommendation for the circuitry is to use the full wave rectifier bridge since the full wave rectifier bridge can rectify the voltage and the voltage will become smooth DC (direct current) output voltage. The output voltage will become larger and it will also produce a smoother output waveform. The energy harvester is suitable for low power application and thus using full wave bridge rectifier may produce larger voltage accumulation.

\section{References}

1. N. H. Samrat, N. B. Ahmad, I. A. Choudhury, and Z. Taha, "Prospect of wave energy in Malaysia," 2014 IEEE 8th International Power Engineering and Optimization Conference (PEOCO2014), (2014), pp. 127-132.

2. Bahaj, A. S., Generating Electricity from the Oceans. Renewable and Sustainable Energy Reviews, 15, 3399-3416, (2015).

3. O.-S. O. Design, "Ocean Wave Energy Harvesting.” WORCESTER POLYTECHNIC INSTITUTE, (2015).

4. B. A. Nasir, "Design Considerations of Micro-hydro-electric Power Plant," Energy Procedia, 50, pp. 19-29, (2014). 
5. R. Caliò, U. B. Rongala, D. Camboni, M. Milazzo, C. Stefanini, G. De Petris, and C. M. Oddo, "Piezoelectric Energy Harvesting Solutions," pp. 4755-4790, (2014).

6. R. Caliò, B. U. Rongala, D. Camboni, M. Milazzo, C. Stefanini, G. de Petris, and M. C. Oddo, "Piezoelectric Energy Harvesting Solutions," Sensors, 14 (3), (2014).

7. J. Siang, M. H. Lim, and M. S. Leong, "Review of vibration-based energy harvesting technology: Mechanism and architectural approach,” Int. J. Energy Res., 42 (5), pp. 1866-1893, (2018.

8. H. S. Kim, J.-H. Kim, and J. Kim, "A Review of Piezoelectric Energy Harvesting Based on Vibration,” Int. J. Precis. Eng. Manuf., 12 (6), pp. 1129-1141, Dec. 2011.

9. T.-C. Yuan, J. Yang, and L.-Q. Chen, "Nonlinear dynamics of a circular piezoelectric plate for vibratory energy harvesting," Commun. Nonlinear Sci. Numer. Simul., 59, pp. 651-656, (2018).

10. Y. Tianchen, Y. Jian, S. Ruigang, and L. Xiaowei, "Vibration energy harvesting system for railroad safety based on running vehicles," SMART Mater. Struct., 23(12), (2014).

11. Khaligh, A., Zeng, P., \& Zheng, C., Kinetic Energy Harvesting Using Piezoelectric and Electromagnetic Technologies, IEEE Transactions on Industrial Electronics, 57(3), 850-860. (2010).

12. Vatansever, D., Hadimani, R. L., Shah, T., \& Stores, E., An investigation of energy harvesting from renewable sources with PVDF and PZT., Smart Materials and Structures, 20(5), (2011).

13. Wu, N., Wang, Q., \& Xie, X., Wind energy harvesting with a piezoelectric harvester. Smart Materials and Structures, 22(9), (2013).

14. Raymond A. Serway Bernoulli's Principle - Physics for Scientists and Engineers, Fourth Edition, Vol.1, Saunders College Publishing, p. 422, p.434, (1996).

15. F. P. Miller, A. F. Vandome, and J. McBrewster, Bernoulli's Principle. Alphascript Publishing, (2010). 